\title{
Economía solidaria y territorio: Complejizando la propuesta de análisis territorial de Coraggio
}

\author{
Eduardo Enrique Aguilar Hernández \\ Red Nacional de Investigadores y Educadores en Economía Solidaria y Cooperativis- \\ mo -Redcoop México, Guadalajara, México. \\ Email: eduardoaguilar.h@hotmail.com
}

\begin{abstract}
Resumen: La economía solidaria se está consolidando como una partícula de un paradigma emergente alternativo al de la modernidad capitalista, por lo que se hace preciso generar herramientas analíticas hacia este tipo experiencias. En el presente trabajo se complejiza el análisis territorial bajo la economía solidaria propuesto por Coraggio con el objetivo de ir develando la serie de relaciones de poder que conforman el entramado territorial. Dicha develación permite tener un entendimiento amplio sobre las dinámicas que acontecen entre actores y el entorno geográfico donde se está produciendo socialmente el territorio
\end{abstract}

Palabras clave: Economía solidaria, territorio, producción social del territorio, modernidad.

\section{Solidarity economy and territory: Completing the proposal of territorial analysis of Coraggio}

Abstract: Solidarity economy is consolidating as a particle of an emerging paradigm alternative to that of capitalist modernity. Therefore, it is necessary to generate analytical tools applicable to this type of experiences. In the present work, the territorial analysis under the solidarity economy proposed by Coraggio is problematized with the objective of unveiling the series of power relations that make up the territorial framework. This disclosure allows a broad understanding of the dynamics that occur between actors and the geographical environment where the territory is being produced socially. modernity.

Keywords: Solidarity economy, territory, social production of territory,

\section{Economia solidaria e território: Complexificando a proposta da análise territorial de Coraggio}

Resumo: A economia solidaria se está consolidando como uma partícula de um paradigma emergente alternativo àquele da modernidade capitalista, pelo que se faz preciso gerar ferramentas analíticas para este tipo experiências. Neste trabalho se complexifica a análise territorial sob a economia solidaria proposta por Coraggio com o objetivo de ir desvelando a serie de relações de poder que conformam a tessitura territorial. Dito desvelamento permite ter um entendimento amplo sobre as dinâmicas que acontecem entre atores e o entorno geográfico onde se está 
produzindo socialmente o território.

Palavras-chaves: Economia solidaria, território, produção social do território, modernidade.

\section{Introducción}

El territorio ya no se visualiza solamente como un componente meramente geográfico sino una serie de entramados complejos "la dinámica de dominio-control-posesión-exclusión del territorio supone una relación social que lo produce y mantiene desde una forma y un ejercicio de poder. El territorio es un espacio construido por relaciones de poder, ya sea como dominio o resistencia al mismo” (Díaz, 2015) que involucran a los actores y sujetos, la geografía y su interrelación "es espacio apropiado, espacio hecho cosa propia, en definitiva, el territorio es instituido por sujetos y grupos sociales que se afirman por medio de él” (Porto-Gonçalves, 2009)

En esa lógica, Manzanal (2007) los llama territorios de la modernidad donde sostiene que los actores tienen la capacidad de modificar su entorno "Los sujetos buscan transformar o 're-construir' su realidad y las instituciones respectivas, para ponerlas al servicio de derechos universales [...] los sujetos son actores que se mueven dentro de los fundamentos de la modernidad" (Manzanal, 2007: 24)lo que se pretende aquí, es ofrecer herramientas para que los actores entiendan que son actores dentro de la modernidad y que por ende, reproducen el espacio territorial dentro de una lógica antropocentrista o con una racionalidad economicista/instrumental, es decir, los actores bajo la matriz civilizatoria de la modernidad producen el territorio con una visión que deja a la naturaleza en un plano de instrumento o de recurso al servicio del ser humano.

El resultado de dicha visión se puede observar en la gran crisis ambiental que se puede vivir hoy en día. En cambio, es palpable que la producción del territorio es distinta en aquellas poblaciones que difieren de la visión centrista de la matriz civilizatoria de la modernidad. Los ejemplos son claros, en diversas comunidades amerindias con principios agroecológicos o del buen vivir, se pueden encontrar caracterizaciones radicalmente distintas a las de la ciudad urbana moderna. La cuestión aquí es ¿cómo analizar los territorios que están inmersos en las matrices civilizatorias que tienen principios distintos a los de la modernidad?

\section{Economía solidaria y territorio}

Aquí se pretende ir construyendo la respuesta a esa pregunta analizando tan solo una partícula de estos paradigmas civilizatorios emergentes: la economía solidaria, la cual es una alternativa que cuenta con bases que contradicen al sistema económico capitalista y por lo tanto, al paradigma de 
la modernidad. En otras palabras, la economía solidaria se cataloga como una alternativa que combina el quehacer socioeconómico y sociopolítico (Mutuberría, 2008) eso quiere decir, que en su ámbito socioeconómico reafirma la voluntad de vida de las personas, pues es capaz de satisfacer necesidades (las cuales son negatividades). En otras palabras, cuando el sistema económico niega las negatividades (las faltas) con satisfactores (la negatividad del hambre se niega con alimento) surge la afirmación de la vida humana (Dussel, 2006:24). Pero además, en su sentido sociopolítico, la economía solidaria ofrece la capacidad de construir consensos que crean acciones que llevan a la promover la reproducción de la vida de los individuos.

Esta capacidad de consensos conforma un poder que se ejerce a través de una política positiva. La política en sentido positivo según Dussel (2006) es "una actividad que organiza y promueve la producción, reproducción y aumento de la vida de sus miembros” (p.24) de esa manera, que el componente sociopolítico de la economía solidaria la diferencia de las otras propuestas pues "aplica los valores democráticos a todo tipo de actividad económica” y además este tipo de opción sociopolítica "es totalmente incompatible e inconciliable con el capitalismo” (Singer, 2008) por lo que aquí se sostiene que esta opción económica alternativa es disruptiva al sistema capitalista dominante.

Es de esa manera, que existen investigadores sociales como José Luis Coraggio que cuenta con investigaciones sobre cuáles son los actores que inciden en el territorio y cuál es el papel que la economía solidaria juega en la construcción del territorio. En sus reflexiones Coraggio (2011) indica la necesidad de pensar al territorio de manera compleja "[el] territorio como un todo complejo natural, que incluye a la población humana y sus asentamientos como una especie particular de la vida, y otra que, puesta a entender los comportamientos de los seres humanos, incorpora los conceptos de comunidad y sociedad como componentes del territorio, que se vuelve así una categoría abarcadora y abarcada, donde procesos naturales y sociales se interpenetran.”(p. 281) Es decir, pensar el territorio tiene que ser una tarea dialógica y continua, donde está continuamente siendo producido por la interacción entre individuos, y los individuos producidos por el territorio existente "El territorio apela a la complejidad y riqueza de lo real, que sería empobrecida por una teoría que además llevaría a intervenciones mal orientadas” (Coraggio, 2011: 277).

Dentro de la tarea de pensar el territorio, aquí se plantea utilizar la conceptualización "producción social del territorio" para ofrecer el análisis de la economía solidaria sobre el territorio. La producción social del territorio está ligada a actores heterogéneos que conviven dentro de un espacio con geografías diversas, la imbricación de relaciones, acciones dentro del espacio producen cambios en el entorno las cuales pueden ser percibidas físicamente o intangiblemente. Desde los cambios macroestructurales de infraestructura como puentes, carreteras, drenajes o aeropuertos, hasta aquellas expresiones de recuperación de espacios públicos, grafiti, 
reforestaciones, ocupaciones de espacios o intervenciones urbanas; son producciones territoriales emergidas de una disputa de relaciones de poder insertos en un ámbito geográfico.

Diversos estudios (López de Sousa, 1995; Manzanal, 2007; Padilla, 2012) llaman a este proceso territorialidad, no obstante, dentro del presente trabajo se utiliza la categoría de producción social del territorio como indicación de un proceso continuo que hace referencia directamente a individuos que actúan sobre un sustrato material y cuentan con un objetivo práctico, es decir, son actores en calidad de agentes que están produciendo continuamente el territorio bajo un paradigma civilizatorio. Dentro de la modernidad, los colectivos sociales no ejercen su poder sobre un espacio solamente para el control o para el ostentación del mismo, cuando un colectivo social ejerce un poder sobre un espacio es para darle un uso al espacio, el espacio es producido porque tiene como objetivo obtener un usufructo de dicho espacio, entonces, surgen disputas entre colectivos diversos que se encuentran sobre un mismo espacio o espacios aledaños, en el fondo, los conflictos territoriales surgen por antagonismos entre las formas distintas de producir el espacio.

Los actores principales dentro de la producción social territorial explicados por Coraggio (2011) son tres principales: el Estado, el capital y los sectores populares, cada uno con distinta lógica. Menciona que el Estado "tiene un principio jerárquico territorial de organización [...] es el resultado de procesos ecológicos, políticos, sociales, económicos y culturales y tiene una gran inercia y resistencia al cambio.” Por su parte el capital tiene una relación "mediada por los flujos de valor, información y productos. El capital fetichiza al territorio, como un valor de uso-medio de producción o valor de uso-depósito del que extrae medios de producción o trabajo, o en que vierte sus residuos [...] su tendencia es superar todas las barreras territoriales, a homogeneizar los territorios” y por último los sectores populares tienen una lógica de "búsqueda de condiciones de reproducción de la vida en sociedad” subordinadas a las fuerzas del Estado y del capital (Coraggio, 2011:309-311)

\section{Complejizando el análisis territorial de Coraggio}

Empero lo anterior, hace falta complejizar el rol de los actores en el proceso de producción del territorio para poder entender el cómo se entraman las relaciones de poder. $\mathrm{Ni}$ el Estado, ni el capital ni las clases populares son monolíticos ni mucho menos homogéneos, de hecho, tienen características y contradicciones internas, pueden ser modificadas y se encuentran en constante transformación.

En su propuesta Coraggio (2011) hace el análisis de la afirmación anterior solamente indicando que los sectores populares actúan de manera no uniforme "las estrategias de reproducción de las unidades domésticas populares se ubican en el campo compartido con las lógicas del sistema 
interestatal y del capital global” y continúa señalando que éste sector se encuentra inmerso en una construcción social con otra lógica "la relación con los centros de venta y o de compra, con los lugares de trabajo, los desplazamientos para ir a la escuela o a establecimientos de salud, están muy pautados tanto por la lógica ordenadora de la administración pública y sus políticas, como por requerimientos de rentabilidad del capital” (Coraggio, 2011:311)

Efectivamente, se coincide en que el sector popular, es heterogéneo, y es por esa misma razón que la categoría se precisa complejizar. Se propone, separar al sector en dos ya que no todo el sector popular cuenta con las herramientas necesarias para producir un espacio geográfico, por lo tanto, primeramente, se hace reflexión sobre el colectivo habitante ${ }^{1}$ que se sitúa dentro de un espacio geográfico delimitado, se afirma que en caso de la producción social del territorio solamente el colectivo habitante es el que tiene la acción de producción directa. En segundo lugar, el sector popular que se encuentra ajeno al ámbito geográfico delimitado que puede tener diversas maneras de influir desde la distancia, por ejemplo, al ejercer presión sobre acción estatal o dotando de herramientas al colectivo habitante para su empoderamiento, es decir, ejerce una acción de producción indirecta.

El colectivo habitante, como ya se explicó anteriormente, es parte del territorio, no sólo ha intervenido sobre el ámbito geográfico sino que ha sido influenciado por el mismo, por tanto, cuando existe una disputa territorial el colectivo habitante puede tener diversas actuaciones entre sus actores. Para revisar esto hay que retomar la investigación de Giménez (1999) donde hace un análisis de la identidad regional y clasifica a los actores en: apáticos y resignados; migrantes potenciales; modernizadores; tradicionalistas y regionalistas. Si bien todos son parte del colectivo habitante, los que entran dentro de la disputa territorial son los modernizadores, los tradicionalistas y los regionalistas, para este estudio no se toma en cuenta el papel de los apáticos ni los migrantes potenciales por su incapacidad directa de incidir, aunque probablemente tengan un papel relevante que se va formando en el transcurso del tiempo.

Más allá de las identidades formadas de cada uno de los agentes del sector popular, es pertinente revisar el proceso de construcción de la subjetividad, ya que es clave para la reconstrucción identitaria y por tanto, fundamental para el entendimiento de los conflictos territoriales. Por tanto, un colectivo habitante, está en continua relación con estructuras territoriales del capital y de la acción estatal que influyen dentro de su constitución como individuo, pero a su vez, realiza acciones acordes con la reproducción ampliada de la vida que no va acorde con las estructuras capitalistas, y que a nivel interno del sujeto se genera una subjetividad contradictoria. Laura Collin (2015) lo ejemplifica en el análisis que realiza con la lógica ampliada del capitaly la lógica reproductiva "la racionalidad reproductiva presupone la mutua dependencia de los seres humanos [...] la reproducción ampliada del capital es la sustitución de la satisfacción de necesidades, como fin por 
la generación de riqueza” por lo tanto “a la lógica reproductiva se opone la lógica de la reproducción ampliada del capital” (Collin, 2015: 101-102)

Esta subjetividad contradictora da pie a la constitución de identidades propuesta por Giménez (1999) agrupadas en dos grandes regionalistas/ tradicionalistas y los modernizadores. Por eso es importante, trabajar desde las subjetividades "Cualquier esfuerzo de oposición al neoliberalismo se debe tomar seriamente el proceso de subjetivación neoliberal - como el discurso, lenguaje y representación” (Rice, 2013:845-861) ya que de éstas es de donde emergen las condiciones materiales y estructuras sociales que dan forma a las conductas individuales y transforman las relaciones sociales (ibid).

El mismo tratamiento de complejización se tiene que hacer hacia el Estado y el capital. Por su parte, el Estado, es un concepto amplio que abarca muchas vertientes, es por eso que se propone utilizar la categoría acción estatal como aquella intervención del Estado sobre un espacio geográfico. Según Coraggio (2011) el papel del Estado es el de hacer una "regionalización” ya que tiene "un principio jerárquico territorial de organización” para crear “regiones político-administrativas” (2011: 309). Sin embargo, y sin contradecir lo expuesto, se precisa indicar que en la acción estatal, dentro de sus poderes organizativos existe implícitamente un proyecto de transformación espacial. De esa manera, la acción estatal tiene características específicas de transformación por las distintas funciones que se le han asignado, por ejemplo, las funciones legislativas, ejecutivas o fiscales; dentro del Estado moderno, estas funciones pueden ser ocupadas por distintos colectivos, tanto el popular como el del capital, es por esa razón que aquí se sostiene el argumento de que el poder emergente de la acción estatal es ambivalente, ya que, puede ser provechosa para el florecimiento de los proyectos nacidos del sector popular o para el capital.

Ante lo anterior, se hace preciso indicar que, la acción estatal no está sujeta a una dirección concreta, puede estar determinada por la reproducción ampliada del capital o por la lógica reproductiva, por tanto, se le cataloga como una estructura a la cual se puede tener acceso (De Sousa Santos, 2006; Dussel, 2008; Cruz, 2011) y que a su vez tiene incidencia dentro de la disputa por el territorio. Así Cruz (2011) lo ejemplifica señalando que el Estado no es un bloque monolítico y que, si es verdad que los oligopolios detentan poder económico, asimismo es verdad que la democracia abre espacios que los sectores populares, bien organizados y movilizados, pueden disputar. La acción estatal, puede convertirse en un puente entre los distintos colectivos civiles para lograr cambios macroestructurales de infraestructura o expresiones locales de apropiación territorial. La acción estatal tiene distintas caras como la municipal, la estatal o la nacional, y estas no necesariamente están coordinadas o trabajan para el interés de un solo actor, es decir, tanto los sectores populares como los del capital disputan los diferentes espacios de la acción estatal.

El siguiente actor a analizar es el capital, éste es un actor amplio y 
abstracto, por lo que se hace necesario hacer ciertas precisiones. Para poder construir una categoría que ofrezca una relación directa con el territorio, es menester visibilizar el hecho de que son distintos colectivos los que tienen el poder económico capitalista, y que, inclusive entre ellos mismos, se encuentran en competencia constante para seguir obteniendo beneficios económicos. Estos colectivos pueden están coordinados o no para producir un tipo de territorio, pueden tener origen regional, nacional o trasnacional y por tanto, están a la distancia ${ }^{3}$, no forman parte del colectivo habitante, ni de los sectores populares.

A estos colectivos con poder económico de capital se les nombrará como colectivo beneficiado, teniendo en cuenta que es heterogéneo, en competencia entre los participantes que lo conforman, pero sí obteniendo beneficio aún estado a la distancia, o fuera del territorio. Este colectivo beneficiado está enmarcado en la conceptualización de automatismos financieros del filósofo Franco Berardi citado por Fernández-Savater:

"la clase financiera -o, mejor dicho: el conjunto de los automatismos financieros- se enriquece a través de la destrucción del valor producido, a través de la privatización de los bienes comunes. La plusvalía de las financias es una minusvalía desde el punto de vista social”.(Fernandez-Savater, 2014)

Además refuerza el argumento de encontrarse fuera del espacio geográfico que está produciendo

“la burguesía tenía una fuerte territorialización ciudadana y nacional, mientras que la clase financiera es una clase totalmente desterritorializada, incapaz de identificarse con ningún lugar específico”.(Fernandez-Savater, 2014) ${ }^{4}$

El colectivo beneficiado utiliza diversas normas y agentes para poder producir el territorio dentro de cierta geografía o tiene poder para manejar la acción estatal y desde ahí producir el territorio, dentro de la actualidad, tales expresiones se dan con diversas contextualizaciones discursivas, por ejemplo, bajo la idea de desarrollo se han conformado clusters industriales que producen un cierto tipo de territorio, es ilustrativa la definición hecha por Porter "El cluster es un grupo de compañías interconectadas e instituciones asociadas en un campo particular geográficamente próximas, ligadas por comunalidades y complementariedades. El alcance geográfico puede oscilar entre una ciudad, un Estado hasta un país o hasta un grupo de países vecinos” (Porter, 2000). De igual manera, también se encuentran apropiaciones territoriales y despojos para los emprendimientos del colectivo beneficiado, se puede mencionar el fracking, los megaproyectos de minería o de hidroeléctricas.

Entendiendo entonces que, las heterogeneidades de los actores que están en constante interacción generan la contradicción subjetiva de los individuos queproducen el territorio, se hace posible captar el sentido de 
las disputas, las cuales se presentan en diversos ámbitos con distintos niveles de visibilidad ${ }^{5}$, por ejemplo:

a) La lucha entre los agentes del colectivo beneficiado en contra del colectivo habitante;

b) La de los intereses del colectivo beneficiado directamenteen contra del colectivo habitante;

c) La de los intereses del colectivo beneficiado sobre la acción estatal en contra de los intereses del sector popular y/o el colectivo habitante, $y$;

d) La de los distintos actores con visiones heterogéneas dentro del colectivo habitante.

La producción social del espacio está definida por los distintos proyectos políticos-económicos-culturales de los colectivos sociales insertos en ese ámbito geográfico. Es decir, las relaciones tanto discursivas como productivas tienden a modificar el espacio físico, pero también crean rasgos característicos del territorio como institucionales o ritualísticos. De esa manera, los ámbitos urbanos y rurales se distinguen por sus características territoriales que pueden ser percibidas a simple vista, desde las áreas de cultivo hasta las grandes avenidas o rascacielos, espacios que inclusive han ido cambiando históricamente: el ágora, el monasterio, los parlamentos o los centros bursátiles permiten visualizar las relaciones de poder dominantes durante cierto periodo de tiempo.

En la actualidad, la modernidad, como proyecto civilizatorio, y el sistema económico capitalista, han generado una contradicción fundamental dentro del territorio: por una parte, se sabe bien que la configuración del espacio ha servido para la propia reproducción de la modernidad y de la economía capitalista y que dicho espacio no provee los elementos para la realización plena de las personas que viven en él, además de limitar la reproducción de la vida de la gente a estándares que imponen los grandes capitales. Lo anterior es claro cuando se analiza el espacio urbano, es en las grandes ciudades donde se han asentado los centros de actividad del capital, Nueva York, Londres, Berlín, Hong Kong o Tokio, pueden ser los ejemplos para visualizar los espacios de reproducción del mismo sistema y de limitación de la vida plena de las personas.

La cuestión que se sostiene aquí es que la contradicción consiste en que los individuos continúan construyendo es mismo espacio de reproducción de la modernidad/capitalista y continúan ampliándolo conforme a las reglas que dictan el progreso y el desarrollo, esperando a que se cumplan sus promesas de mejoramiento del nivel de vida. Ya es un hecho de que la población a las urbes superó a los que moran en el ámbito rural, y es un fenómeno que parecer no tener fin.

Esta contradicción se explica fundamentalmente por dos cosas. Por una parte, la correlación de fuerzas es desigual, existe un colectivo beneficiado — clases dominantes — el cual influye sobre la producción social 
territorial aunque no se encuentre físicamente dentro del mismo. Dicho colectivo beneficiado tiene suficientes recursos para transformar, producir e imponer acciones y voluntades. Por otra parte, existe un colectivo habitante, que se encuentra físicamente dentro de diversos entornos geográficos donde la subjetividad de los individuos conformantes se ha modificado de tal manera que sea acorde a los principios de la modernidad y del sistema económico hegemónico. De igual manera, hay individuos que inmigran a los grandes centros urbanos buscando mejores oportunidades (se convierten en nuevos miembros del colectivo habitante) estas personas también son subsumidas dentro de la lógica moderna/capitalista para seguir reproduciendo al sistema.

Existe así un proceso de transformación subjetiva del colectivo habitante; Bautista (2014) lo ejemplifica de la siguiente manera: “... el capitalismo, cuando produce la mercancía y el dinero capitalista, lo que hace es también producir la subjetividad del sujeto por la repetición constante de este proceso". (Bautista, 2014: 213)Es decir, los sujetos del colectivo habitante han introyectado lo promulgado por un sistema que genera desigualdades donde los mismos individuos se ven afectados, por lo que, dentro del campo de las relaciones de poder, el colectivo beneficiado se coloca en una posición aún más privilegiada.

Si entendemos que las disputas emergentes de la producción social del territorio son por los distintos intereses de los colectivos pero que, además, hay una correlación de fuerzas desigual donde la lógica está a favor de la modernidad/capitalista (introyección de los principios normativos en la subjetividad de todos los actores).

En este sentido, la organización rural y urbana son puntos dignos de análisis. Se puede vislumbrar que dentro del ámbito rural no todos los territorios han sido modificados con la lógica moderna/capitalista y es importante señalar que dentro del ámbito urbano aquellos territorios que en un primer momento fueron construidos con la visión dominante se han ido transformando cuando los principios normativos del colectivo difieren a los de la visión hegemónica.

\section{Subjetividad e identidad}

Entonces, para poder visualizar una producción social del territorio distinta es imprescindible entender que los principios normativos de los colectivos se apropian dialógicamente entre el individuo y el grupo, existiendo un proceso de transformación de la subjetividad e identidad. Dicho proceso se comienza mediante el cambio discursivo y político. Veronesse (2009) indica:

“No podemos pensar los procesos de subjetivación como exclusivamente individuales, vividos por el sujeto en la construcción de su mundo interno, pero sí como procesos de socialización, siempre 
relacionales, generadores de formas de sociabilidad diversas. El sujeto se construye a través de los procesos socializadores en los cuales se inserta activamente y de los cuales resultan sus comportamientos, emociones, congniciones y acciones”(Veronese, 2009)

El cambio discursivo y político que rompe con los principios normativos de la modernidad/capitalista es existente; dicho cambio es latente en contextos civilizatorios que fueron negados por la modernidad ${ }^{6}$. Cuando se rescata la dimensión territorial de la economía solidaria, en un sentido de afirmación de la vida, entonces se tiene que analizar desde un ámbito geográfico concreto ${ }^{7}$, donde los colectivos de personas viven y conviven cotidianamente. En ese sentido, Azam (2009) indica claramente que uno de los proyectos de la economía solidaria es la "reapropiación política de los territorios, en cuyo interior las decisiones acerca de los modos de producir, consumir, utilizar y repartir las riquezas” ya que estas "pueden ser discutidas colectivamente” (Azam, 2009) y de igual manera Rincón Gamba (2012) afirma que:

"Las prácticas de economía social y solidaria, entendidas como prácticas socioeconómicas conscientes alrededor de la construcción de otra economía/otra sociedad, tienen posibilidad de concretarse y enraizarse en determinados territorios, según las tensiones particulares que existan en dicho espacio entre el Estado, el capital y el sector popular” (Rincón Gamba, 2012:34)

La localización territorial de la economía solidaria da pauta para entender las disputas existentes entre los diversos actores y por ende diversas subjetividades bajo diferentes cuadros normativos. Esta afirmación se refuerza con la investigación de Díaz (2015), pues indica quelas economías solidarias tienden a encontrar en el territorio la proximidad requerida para su desarrollo y la consolidación del mismo frente a las economías del capital. Por su parte, Rincón Gamba (2012) cita a Coraggio para ilustrar los papeles de los colectivos que construyen distintos proyectos económicos: "Según Coraggio, el capital actúa bajo el fin de la acumulación ampliada de capital, el Estado bajo el fin de la acumulación de poder político para el ejercicio de gobernabilidad y el sector popular bajo una racionalidad reproductiva" (Rincón Gamba, 2012:26) cuestión que también había afirmado con anterioridad Lefebvre (2013): “Cada sociedad [...] produce un espacio, su espacio [...] ¿Cada sociedad? Sí, cada modo de producción con algunas de sus relaciones de producción específicas, con sus variantes apreciables." (Lefebvre, 2013: 90-91) Además, el mismo autor resalta lo siguiente:

"Por lo que concierne a la lucha de clases, su papel en la producción del espacio es fundamental, pues clases, fracciones y grupos de clases conforman los agentes de la producción espacial. La lucha de clases pude leerse en el espacio actualmente más que nunca. A decir verdad, sólo ella impide la extensión planetaria del espacio abstracto disimulando todas las diferencias [...] Desde luego, las acciones políticas de las minorías forman parte de esta lucha”(Lefebvre, 2013: 113) ${ }^{8}$ 
Por tanto, el análisis de las relaciones territoriales de los colectivos insertos dentro de un cierto ámbito geográfico, las transformaciones y procesos que recrean en ese espacio son de relevancia para entender las luchas emancipatorias pues "....quienes entiendan el territorio, quienes puedan hacerlo más inteligible, estarán en mejores condiciones de intervenir, de gestionar, de contribuir a desarrollarlo, a transformarlo, a ser más inteligentes con su territorio" (Bozzano, 2012)

Para dar seguimiento a la localización territorial, es necesario entender la praxis de la lógica económica alternativa, la cual es diversa, GibsonGraham (2011) hace un recuento muy interesante sobre ésta diversidad. Dentro del mundo de las transacciones se establece la multiplicidad, desde aquellas donde no existe el mercado, aquellas dentro del mercado convencional y otras dentro de los mercados alternativos. Las transacciones donde no existe mercado son parte de las alternativas económicas y éstas no pueden ser conmensurables:

“Tal vez la forma prevalente de intercambio es la gran variedad y el volumen de las transacciones no mercantilesque nos sostienen a todos nosotros [...] En estas transacciones no hay reglas de conmensurabilidad y no puede haber ningún cálculo formal de cuánto se comparte [...] las normas y reglas culturales se reflejan en cómo se llevan a cabo estas transacciones (Gibson-Graham, 2011: 176-177)

Dentro de las transacciones de mercado convencional, los intercambios tienen que tener una calidad de equivalenciales pero tienen la característica de que "los bienes y servicios se intercambian y la conmensurabilidad se negocia y acuerda socialmente” (Gibson-Graham, 2011: 178). Dentro de los mercados alternativos, se pueden encontrar las monedas alternativas, el comercio justo, el intercambio cooperativo, los créditos alternativos, y el trueque, para este último indican "es otra forma prevalente de transacción en la que las mercancías consideradas como equivalentes en valor, por los productores o comerciantes, se intercambian sin recurrir al dinero" (GibsonGraham, 2011: 179). Junto con las transacciones se tiene que pensar en la distribución de los bienes y servicios, de tal manera que, la visión se amplía no solo a la eliminación del lucro de los intermediarios sino al desarrollo de los medios de distribución sustentables.

Otra de las formas donde se encuentra la lógica económica diversa y solidaria es dentro del trabajo, en primer lugar, el proceso de visibilización del trabajo no remunerado "que se lleva a cabo en el hogar, la familia, el vecindario o en la comunidad en general [...] la recompensa para estos trabajos llega en forma de amor, apoyo emocional, protección, compañía y autoestima [...] también se presentan en el consumo o disfrute de lo que se ha producido" (Gibson-Graham, 2011: 180-182)

Por otra parte, dentro del trabajo remunerado se tienen que tomar en cuenta aquella donde el pago del trabajo es justo o existen pagos alternativos, así hay personas que trabajan a cambio de pagos en especie o que 
trabajan en cooperativas donde pueden decidir sobre la gestión del excedente. Las cooperativas son una parte fundamental para la lógica económica solidaria pero no son las únicas figuras empresariales donde "la propiedad y la producción se configuran de manera diferente” (Gibson-Graham, 2011: 184) en este sentido de multiplicidad de iniciativas empresariales, Paul Singer (2011) las cataloga como empresas solidarias que "niega la separación entre el trabajo y posesión de los medios de producción [...] el trabajo y el capital se funden porque todos los que trabajan son propietarios de la empresa y no hay propietarios que no trabajen en ella [...] su finalidad básica no maximizar el lucro, sino la cantidad y la calidad del trabajo” (Singer, 2011: 63-64), entonces hay que centrarse en las "diferentes unidades de producción (ya sea negocios, instituciones gubernamentales, granjas y hogares) [que] generan y distribuyen la riqueza producida" (Gibson-Graham, 2011: 184) La categoría genérica de análisis de este tipo de actividades se les cataloga como Emprendimientos Económicos Solidarios (Gaiger, 2009) el cual se utilizará dentro del presente trabajo pues permite hacer un manejo amplio de las iniciativas encontradas alrededor de las economías alternativas.

De igual manera, dentro de la diversidad de la economía solidaria, y como base fundamental se encuentra el consumo solidario que "se da cuando la selección, de lo que consumimos, la hacemos no sólo considerando el bienvivir personal, sino también el bienestar colectivo” (Mance, 2008: 42) es un acto político y consciente para poder reproducir un sistema con lógica solidaria, las cooperativas de consumo son expresiones de la organización de un consumo distinto.

La financiación es otro de los puntos fundamentales para la lógica económica solidaria, los bancos éticos, las cajas de ahorro y préstamo son ejemplos que se ofrecen en la práctica de la economía solidaria.

Todas estas manifestaciones enmarcadas en la lógica económica alternativa, tienen principios normativos (expuestos ya por Dussel) pues son expresión de la construcción de una economía para la vida es decir, son prácticas que están enfocadas para la "satisfacción de necesidades que hacen posible la vida” (Hinkelammert \& Mora, 2008) y no para la reproducción del capital o la obtención de ganancias.

Ahora, si la idea es combinar un cuadro normativo acorde a la economía solidaria dentro de un colectivo - habitante o beneficiado - para la producción social del territorio de manera contrahegemónica, se tiene que revisar lo que dice Eidelwein (2009) cuando reflexiona de la reconstrucción de la subjetividad social:

La economía solidaria como un modo de organización de la producción, de la distribución y del consumo, en la perspectiva de un desarrollo económico y social incluyente, como un movimiento social y una política pública, fundamentada en valores diferentes a los que fundamentan la economía de mercado, puede presentarse como un 
dispositivo que contribuye para la gestión de una subjetividad social en la dirección de la (re)producción de modos de vida más justos y solidarios (Eidelwein, 2009)

Por lo anteriormente expuesto, se visualiza un espacio de contradicción donde la producción del espacio es ambivalente, es decir, la subjetividad que tiene introyectada una práctica capitalista tenderá a construir socialmente el espacio acorde a lo que dicta el capital, pero cuando se insertan prácticas de economía solidaria a la vez se re-construye el espacio conforme a una racionalidad de la reproducción. La contradicción se hace palpable en la expresión de las relaciones de poder existentes dentro de los actores enlistados en la producción del territorio, como se mencionó anteriormente, si bien el territorio surge por la convergencia y divergencia de las relaciones de poder entre actores sociales, dentro de estos colectivos sociales son heterogéneos y habrá diferencias que se manifiestan en discursos, lenguaje, símbolos culturales y acciones.

En primer témino, cuando se habla de los sujetos conformantes de los diversos colectivos: habitante, benefiado o del sector popular, ya descritos anteriormente, es necesario entender que si bien son todos y todas heterogéneos están imbuidos dentro de la lógica de la modernidad/capitalista, por tanto, se les considera sujetos sociales moderno-capitalistas ${ }^{9}$. "Para que surgiera el sujeto social capitalista, la idea de la acumulación (ahorro) de dinero, y su inversión, para ganar más dinero, debía aparecer primero como aspiración, como deseo, y con una justificación” (Collin, 2012: 102) dicha aspiración y deseo fue producida en una relación cíclica con la legitimación de un pensamiento científico hegemónico, es decir, la teoría económica ortodoxa como ciencia que internalizó la separación entre lo público y lo privado y su consecuente división sexual del trabajo. El supuesto de racionalidad instrumental que es central en el enfoque neoclásico implica un sujeto económico homogéneo, ahistórico, desconectado de su comunidad, individualista, maximizador, interesado, egoísta y competitivo. Este sujeto es conocido como homo economicus o el hombre guiado por la racionalidad instrumental y por el objetivo de maximizar su propia utilidad, minimizando recursos (Quiroga, 2009)

El pensamiento moderno, en su fetichización del concepto libertad ${ }^{10}$, ha podido generar habilidosamente las estrategias para que el sujeto social occidental adopte sin cuestionar el modo de vida capitalista. Dentro de éste proceso de construcción del sujeto social se pueden visualizar dos grandes momentos: el discurso y la subjetividad.

Por un lado, el discurso como momento inicial del mundo relacional entre individuos es el comienzo del proceso político para poder articular un proyecto de cooperación para la construcción de la realidad, dicho discurso se encuentra "(y por lo tanto al lenguje) en el centro de cualquier proyecto político” (Gibson-Graham, 2011: 164) es de esta manera que se encuentra una conexión estrecha entre la lingüística, la semiótica y el discurso de los colectivos, ámbitos que se desenvuelven dentro de los intercambios 
relacionales que llamamos cultura. Es decir, todos estos elementos son indisociables y sería inadecuado analizarlos por separado, es menester entender que el lenguaje, los símbolos, el discurso, la política, el poder, y la cultura son parte interrelacionada de la misma formación social, por lo que, para imaginar un mundo más allá del moderno, hay que generar nuevos paradigmas discursivos y todo lo que ello implica. Entender desde el cómo, cuándo y dónde nos posicionarnos es imperante para poder generar nuevos marcos alternativos:

"Los hablantes se dirigen la palabra desde posiciones sociales distintas y su diferente colocación determina cómo lo haben. Para Bordieu $<<$ el lenguaje no sólo es un instrumento de comunicación o incluso de conocimiento, sino también un instrumento de poder. Uno no sólo busca que lo entiendan, sino que le crean, le obedezcan, lo respeten y lo distingan $>>$ [...] el poder decide quién puede hablar, en qué orden, por medio de qué procedimientos discursivos y acerca de qué temas”(Wolf, 2001: 80)

Así, cuando generamos un cierto tipo de discurso de manera consciente estamos fijando una posición y por tanto, estableciendo una relación de poder con el otro, pudiendo ser esta jerárquica-verticalizada u horizontalizada "[el] significado y el poder constitutivo del discurso, que cuestiona las ideas establecidas y las prácticas dominantes [...] demuestra cómo pueden surgir nuevas formas alternavias de práctica y de poder”(Gibson-Graham, 2011: 164) Para poder llegar a ésta posición discursiva consciente, se tiene que entender que, el pensamiento moderno ha establecido un lenguaje de unicidad, por ejemplo, dentro del ámbito económico como en todos los otros ámbitos- ha invisibilizado la diversidad económica haciendo creer que hay un modelo único de economía. "El discurso capitalocéntrico ha colonizado completamente el panorama económico y sus pretensiones universales paracen haberse realizado” (Gibson-Graham, 2011: 166)

“Es por eso que hay que reflexionar sobre el discurso actual, el cómo trabaja, cuáles son los símbolos que utiliza, y qué estrategias utiliza para su propagación. El capitalocentrismo es el discurso económico dominante que otorga un valor positivo a aquellas actividades asociadas con la actividad económica capitalista, como quiera que esta se defina, y les asigna un menor valor a todos los otros procesos de producción y distribución de bienes y servicios, identificándolos en relación con el capitalismo como igual a, opuesto a, complementario a, o contenido en”(Gibson-Graham, 2011: 167)

El sujeto capitalista, introyecta el discurso capitalócentrico, y pone en práctica sus postulados, la mayoría de las veces sin cuestionar la racionalidad existente del capitalismo "Se trata de dos criterios diferentes de racionalidad: uno (efectivo para el capital) es suicida; el otro [...] sería afirmativo de la vida humana” (Dussel, 2014: 234). Dicha introyección no es fortuita, el sistema cultural moderno recompensa o castiga a los individuos 
dependiendo de su actuación, así la racionalidad del hombre exitoso ${ }^{11}$, es contraria a la afirmación de la vida en general:

“si decimos que un sistema 'da prioridad' a tal acumulación incesante [de capital] significa que existen mecanismos estructurales mediante los cuales quienes actúan con alguna otra motivación son, de alguna manera, castigados y son eliminados eventualmente de la escena social, mientras quienes actúan con la motivación apropiada son recompensados y de tener éxito, enriquecidos”(Wallerstein, 2006)

Es de esa manera que desde el discurso, desde el posicionamiento consciente, desde la resignificación de símbolos culturales se puede tener incidencia en el cambio de paradigmas económicos, de género, de ecología, de política, de gobierno, de autoridad, etc.

"Se puede dislocar la unidad y la hegemonía del discurso económico capitalista global neoliberal mediante una proliferación inusual (queering) del panorama económco y la construcción de un nuevo lenguaje de la diversidad económica. Esta dislocación es un prerrequisito esencial en el proyecto de cultivar diferentes sujetos de la economía”(Gibson-Graham, 2011: 167)

Dicho cambio discursivo permite a su vez, la reconstrucción de una nueva subjetividad "Los estudios de subjetividad tendrían, por lo tanto al menos dos refencias la de la subjetividad existente y la de la subjetividad emergente" (Collin, 2012: 99) En los párrafos anteriores se pudo constatar que el sistema hegemónico ha generado un discurso y prácticas capitalistas que los individuos han introyectado, y por tanto cuentan con una subjetividad acorde al sistema, que la han llamado subjetividad capitalística ${ }^{12} \mathrm{o}$ subjetividad del homo economicus(Rice, 2013). En otras palabras, el sujeto colectivo capitalista cuenta con individuos que tienen subjetividades capitalísticas que han sido formadas, justificadas y fortalecidas por el discurso centrista del pensamiento moderno y por el discurso de la economía única capitalista en una reproducción dialógica.

Es muy importante puntualizar que dentro de muchas culturas dichas subjetividades capitalísticas no son puras (Rice, 2013) sobre todo en aquellas donde existen grupos humanos con prácticas no-modernas como los pueblos originarios o algunos del ámbito rural. Si bien el sistema se ha encargado de subsumir a los individuos para eliminar las prácticas no-modernas, éste no ha podido transformar su subjetividad completamente cuando el individuo ha crecido con un pensamiento que tiene un marco normativo con racionalidad reproductiva o acorde a la vida. Por ejemplo, digamos que una persona indígena de la sierra de norte de Puebla migra a Nueva York donde consigue un empleo, ésta persona será subsumida por el sistema económico capitalista donde su corporalidad se venderá como mercancía y su trabajo entonces será ajeno a él -enajenación-. La subjetividad de dicho individuo tendrá que cambiar hacia una que le permita sobrevivir ante su nuevo entorno, no obstante, la subjetividad emergente será contradictoria 
porque existirán dos racionalidades, una que es acorde a la vida y una que es acorde a la del capital. Lo anterior se puede visualizar en los lazos de reciprocidad y confianza que teje con otros individuos con los que comparte rasgos identitarios versus el individualismo y el egoísmo que el sistema económico le está imponiendo que reproduzca. Esta es una lucha constante de las/los individuos por su sobrevivencia y por su reproducción.

De lo anterior, es ilustrativo visualizar que existen procesos inversos, es decir, personas que han nacido dentro de estructuras culturales donde el pensamiento moderno/capitalista es naturalizado, pueden aprender y desarrollar un lenguaje y prácticas con racionalidad acorde a la vida, los cuales generan cambios subjetivos contradictorios que influyen dentro de la construcción de un entorno diferente, un caso se puede revisar en Rice et al (2011) donde personas de "lugares socialmente privilegiados comienzan a trabajar desde un marco de acción que desafía a las estructuras que les dan privilegios” (Rice et al, 2011) el estudio de Rice está refiéndose a personas nativas de los Estados Unidos que han entendido el proceso de la globalización económica y que generan un sentimiento de solidaridad y amor y ofrecen trabajo voluntario para ayudar a mujeres migrantes en la frontera con México. Estas personas, siguen utilizando las herramientas que les ofrecen sus posiciones privilegiadas y aun así pueden generar lazos de reciprocidad. De igual manera es una lucha constante de las/los individuos por su sobrevivencia y por su reproducción.

La clave entonces, para entender la producción social del territorio, es la subjetividad contradictoria existente dentro de los colectivos propuestos a analizar, el entendimiento de que sus posturas no son siempre congruentes y que no responden a una racionalidad en particular permite reflexionar de manera compleja el cómo se constituye su territorialidad y el cómo construir otro tipo de territorio que salga de la "lógica suicida”. Se tiene que trabajar desde la subjetividad y todo lo que eso incluye: discurso, lengua, política, significación, espacios deliberativos, trabajo, identidad, educación, interculturalidad, etc.

"La posibilidad de transformación de la subjetividad, incluye la búsqueda y el encuentro de los 'espacios de resignificación de esa aproiación’ (Veronesse, 2007: 41) Entre los espacios de resignificación el trabajo encontraría un lugar privilegiado como estructurador de la personalidad [...] La construcción de subjetividades renovadas, cobra importancia la constitución de espacios deliberativos y de ejercicio del poder-hacer y de la autonomía como las Asambleas (Fernández, 2003) o las empresas recuperadas”(Collin, 2012: 100)

No existe una receta única, es una combinación de elementos que permiten crear una subjetividad emergente/contradictoria que faculten la generación espacios posibles. De esa manera Díaz (2015) demuestra en su investigación cómo es que las subjetividades de diversos grupos se confrontan y cambian hasta generar nuevas identidades, por ejemplo el de las empresas recuperadas y convertidas a cooperativas muestran: 
"Estas diversas identidades, tienen un sentido construido a través del tiempo, o mejor dicho, diversos sentidos, teniendo a la fábrica como centro o pivote de sus vidas [...] a. 'el sentido proletario' de ser un obrero digno, capaz y bien remunerado, b. 'el sentido de resistencia' para defender lo alcanzado y conquistar nuevas posibildades y c. 'el sentido cooperativista' o de proyecto de vida como cooperativistas coopropietarios”(Díaz, 2015: 269)

O el de las organizaciones campesinas:

"Frente a la gran ofensiva global lanzada en su contra por las vertientes modernizadoras del medio rural -agronegocios y políticos-, los campesinos no sólo han logrado resistir sino que también lo han hecho reivindicando a fondo la validez de su modo de ser: su modo de vida campesino. Este es el núcleo de la identidad campesina y en ella reside su fuerza seductora”. (Díaz, 2015: 273)

\section{Conclusión}

La propuesta de la presente investigación es ofrecer una mirada dialógica de la producción social del territorio, que permita ofrecer un marco referencial para la adecuada reflexión y desde ahí proponer los cambios necesarios para una producción territorial que supere al pensamiento moderno/capitalista y actuar con una racionalidad acorde a la reproducción de la vida. La mirada dialógica y tesis central del presente trabajo se representa en el Gráfico 1, donde se enmarcan los actores que influyen dentro del territorio, junto con los componentes que ya se explicaron a lo largo del texto.

\section{Gráfico 1. Producción social del territorio.}

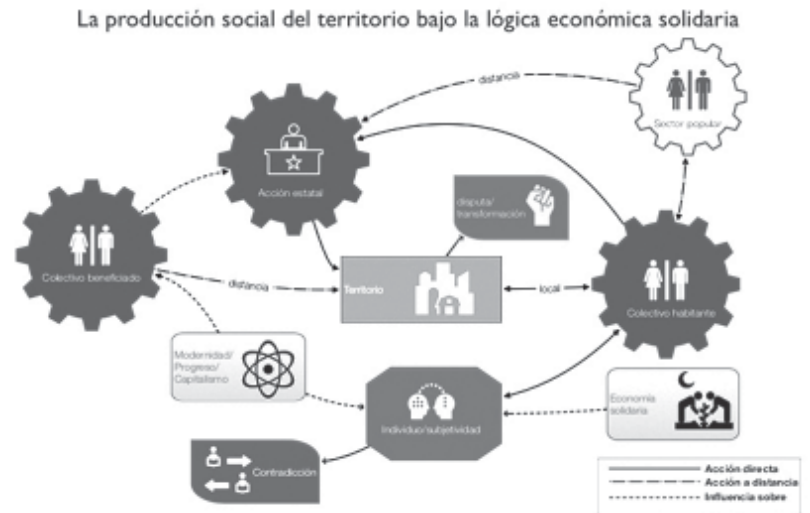

Fuente: Elaboración por autoría propia con información de Coraggio (2011). 


\section{Notas}

${ }^{1}$ Se utiliza el término colectivo para referirse a un grupo de individuos conviviendo juntos independientemente si están conviviendo dentro de un ámbito social o dentro de una comunidad real.

${ }^{2}$ Los migrantes potenciales son susceptibles a ser parte del sector popular que ejerce una acción de producción indirecta. Estudios posteriores podrían investigar la posible fuerza que ejercen estos actores y las relaciones de poder que emanan de sus acciones.

${ }^{3}$ Se hace necesario un estudio completo sobre el espacio que habitan los colectivos beneficiados o el Capital, ya que, el usufructo de la producción de ese espacio es distinto al de cualquier otro espacio habitado por el sector popular. El poder ejercido sobre ese espacio raramente es disputado por el sector popular, y cuándo ese territorio se ve amenazado, los colectivos beneficiados (que en ese caso también se convierten en colectivos habitantes) crean muros que no permiten influencia de los sectores sociales, a veces, ni siquiera la acción estatal.

${ }^{4}$ Si bien Franco Berardi señala a la burguesía y la clase financiera como si fuesen dos grupos distintos, dentro del presente análisis, se entiende a la clase financiera como una transformación de la burguesía pues los detentores del capital en su afán de conseguir mayores ganancias pudieron establecer las reglas de la especulación financiera.

${ }^{5}$ Ante lo anterior, el panorama se complejiza cuando se hace revisión de la dualidad ruralidad-urbanismo.

${ }^{6}$ Los pueblos originarios no tienen que ser considerados como premodernos, "las únicas sociedades premodernas habrían sido las europeas medievales” (Bautista, 2014:

62) en cambio, hasta el día de hoy han mantenido una cosmovisión de equilibrio entre los seres humanos y la naturaleza y el pensamiento moderno no se ha ajustado a su estilo de vida. El comentario va más allá de la idealización de los pueblos originarios, la cosmovisión indígena tiene sus contradicciones, lo que se sostiene es que no se adaptaron, en términos de Villoro, al 'cambio de centro' propuesto por la modernidad.

${ }^{7}$ Esta concepción es contraria a la economía capitalista la cual ha tenido la tendencia a desterritorializar (Azam, 2009) y virtualizar el aspecto económico de producción, distribución y consumo.

${ }^{8}$ Es importante resaltar que Lefebvre utiliza un lenguaje marxista, en este caso, cuando habla de "lucha de clases" se entiende para el presente trabajo a aquellos colectivos sociales que inciden dentro del territorio, y no necesariamente la división dual de proletariado-burguesía, recuperando el sentido de las palabras de Lefebvre en un pensamiento complejo se visualizan diversos sujetos sociales que disputan la producción del espacio, el sector de la economía solidaria desde su perspectiva sociopolítica y socioeconómica es uno de dichos sujetos sociales. Por otra parte, cuando el mismo texto habla sobre "espacio abstracto" cabe aclarar que el autor se refiere al espacio producido por las fuerzas del capital en detrimento del espacio comunitario.

${ }^{9} \mathrm{E}$ inclusive hetero patriarcales. Si bien esta categoría no está dentro del texto principal no es por dejarlo en un análisis secundario sino por falta de dominio del tema, por lo que integrar dicha categoría enriquecería el entendimiento de dicha realidad. 
${ }^{10}$ Ver Dussel (2014).

${ }^{11}$ Se hace referencia al hombre de manera premeditada pues dentro del imaginario moderno se sigue hablando que el hombre es el que tiene que ser exitoso, si una mujer es exitosa es porque está tomando actitudes masculinas. Esto es base al encubrimiento y negación de género que ha existido tomada en base al sistema patriarcal que es más viejo que el pensamiento moderno.

${ }^{12}$ Concepto citado de Guattari por Laura Collin (2012) y Marilia Veronese (2009). 
Polis, Revista Latinoamericana, Volumen 15, No 45, 2016

\section{Bibliografía}

Azam, G. (2009), "Economía solidaria y reterritorialización de la economía”, Pampa. Revista Interuniversitaria de Estudios Territoriales, vol. Año 5, no. 5, p. 69-77.

Bautista, J.J. (2014),¿Qué significa pensar desde América Latina?, Akal, Madrid.

Bozzano, H. (2012), “El territorio usado en Milton Santos y la inteligencia territorial en el GDRI INTI: Iniciativas y perspectivas [en línea]”, XI INTI International Conference La Plata, 17 al 20 de octubre 2012. En Memoria Académica Disponible en: http://www.memoria.fahce.unlp.edu.ar/ trab_eventos/ev.2636/ev.2636.pdf, La Plata, Argentina.

Collin, L. (2012),Economía solidaria: ¿capitalismo moralizador o movimiento contracultural?, COLTLAX/CONACYT, Tlaxcala.

Collin, L. (2015), "La lógica reproductiva como modelo alternativo", in Gracia, M.A. Trabajo, reciprocidad y re-producción de la vida: Experiencias colectivas de autogestión y economía solidaria en América Latina, Miño y Dávila, San Cristobal de las Casas.

Coraggio, J.L. (2011),Economía social y solidaria. El trabajo antes que el capital, Abya-Yala, Quito.

Cruz, A. (2011), 'La acumulación solidaria. Los retos de la economía asociativa bajo la mundialización del capital', Revista de Estudios Cooperativos, vol. 16, no. 1, p. 12-37.

De Sousa Santos, B. (2006), "La Sociología de las Ausencias y la Sociología de las Emergencias: para una ecología de saberes”, Renovar la teoría crítica y reinventar la emancipación social, Buenos Aires.

Díaz, G. (2015),Economías solidarias en América Latina, ITESO, Guadalajara.

Díaz, G. (2015), "Economías solidarias y territorio: hacia un análisis desde la complejidad”, Otra economía. Revista latinoamericana de economía social y solidaria, vol. 9, no. 17, julio-diciembre.

Dussel, E. (2006),20 tesis de política, Siglo XX, Mexico DF.

Dussel, E. (2014), 16 tesis de economía política: interpretación filosófica, Siglo XX, Mexico DF.

Eidelwein, K. (2009),Economia solidária: a produção dos sujeitos (des)necessários. Tesis doctoral, Pontíficia Universidade Católica do Rio Grande do Sul, Porto Alegre. 
Fernandez-Savater, A. (2014), “Bifo: Una sublevación colectiva es antes que nada un fenómeno físico, afectivo, erótico”, ediario.es , 10 octubre.

Gaiger, L.I. (2009), “Emprendimento econômico solidário”, in Cattani, A., Laville, J., Gaiger, L. and España, P. Dicionário Internacional da Outra Economia, Almedina, São Paulo.

Gibson-Graham, J.K. (2011),Una política poscapitalista, Siglo del Hombre Editores/Pontificia Universidad Javeriana, Bogotá.

Giménez, G. (1999), 'Territorio, cultura e identidades. La región sociocultural’, Época II, vol. V, no. 9, junio, p. 25-57.

Lefebvre, H. (2013),La producción del espacio, Capitán Swing Libros, Madrid.

Mance, E.A. (2008),La revolución de las redes. La colaboración solidaria como una alternativa pos-capitalista a la globalización actual, UACM, México DF.

Manzanal, M. (2007), “Territorio, poder e instituciones. Una perspectiva crítica sobre la producción del territorio”, en Manzanal, M., Arzeno, M., Nussbau, B. and (Comp) Territorios en construcción. Actores, tramas y gobiernos: entre la cooperación y el conflicto, Ediciones CICCUS, Buenos Aires.

Mutuberría, V. (2008), “El debate en torno a la Economía Social: discusiones fundamentales desde la perspectiva de los países de la periferia” IDELCOP, no. 83.

Porter, M.E. (2000), “Locations, Clusters and Company Strategy”, en Clark, G.L., Feldman, M. and Gertler, M. Handbook of Economic Geography, Oxford University Press, Oxford.

Porto-Gonçalves, C. (2009), "De Saberes y de Territorios - diversidad y emancipación a partir de la experiencia latinoamericana”, Polis. Revista latinoamericana, vol. 8, no. 22, abril.

Quiroga, N. (2009), “Economías feminista, social y solidaria. Respuestas heterodoxas a la crisis de reproducción en América Latina”, Iconos. Revista de Ciencias Sociales, no. 33, enero, p. 77-89.

Rice, J. (2011), “Crossing Borders: Building Radical Economic Subjectivities along the USA/Mexico Border from Sites of Privilege” , Critical Sociology, no. 37, p. 721-737.

Rice, J. (2013) “Homo Economicus and Consumer Activist Subjectivity: Anti-Capitalist Activism Through Alternative Trade”, New political economy, vol. 18:6, p. 845-861. 
Polis, Revista Latinoamericana, Volumen 15, $N^{\circ}$ 45, 2016

Rincón Gamba, L. (2012), “Territorios y sujetos de la economía social y solidaria”, Otra Economía, vol. 6, no. 10.

Singer, P. (2008), "Relaciones entre sociedad y Estado en la economía solidaria”, Iconos. Revista de Ciencias Sociales, no. 33, enero, p. 51-65.

Singer, P. (2011), “La reciente resurección de la economía solidaria en Brasi”, en De Sousa Santos, B. Producir para vivir. Los caminos de la producción no capitalista, Fondo de Cultura Económica, México DF.

Veronese, M. (2009), “Subjetividade, trabalho e economia solidária”, Revista Crítica de Ciências Sociais, no. 84, marzo, p. 153-167.

Wallerstein, I. (2006),Análisis del sistema-mundo, Siglo XXI, México DF.

Wolf, E. (2001),Figurar el poder: Ideologías de dominación y crisis, CIESAS, México DF.

Recibido: 25.09.16

Aceptado: 01.12.16 